\title{
Entre a Língua e a Literatura: variação linguística e ensino de espanhol
}

\author{
BetWeEn LANGUAgE AND Literature: \\ LINGUISTIC VARIATION AND THE TEACHING OF SPANISH
}

Bruno Rafael Costa Venâncio da Silva* Josilene Pinheiro-Mariz**

Resumo: Tencionamos rediscutir o lugar do texto literário no âmbito do ensino de línguas estrangeiras (ou adicionais). Tal intento está ancorado na necessidade da não dissociação dos dois principais eixos de base do profissional de Letras: Língua e Literatura. Trazemos reflexões que julgamos necessárias para a formação desse profissional, posto que trabalhar entre a língua e a literatura é tarefa delicada e indispensável, sobretudo para o professor da área. Portanto, discutiremos a importância da relação entre língua e literatura, a partir dos estudos da variação linguística no ensino do espanhol no Brasil, tendo-se na literatura o principal ponto de referência para tais ponderações. Primeiramente, discutiremos a variação linguística no ensino de espanhol, partindo-se de uma pesquisa bibliográfica aportada em Moreno Fernández (2010), Vilhena (2013), Andión Herrero (2008) e Lucchesi (2004), e em pesquisa documental embasada nas Orientações Curriculares Nacionais para o Ensino Médio (2006). Ancorados nos estudos de Preti (2004) sobre a variação

\footnotetext{
* Mestre em Linguagem e Ensino pela Universidade Federal de Campina Grande (2015). Doutorando em Filología: estudios lingüísticos y literarios pela Universidad Nacional de Educación a Distancia em Madri (Espanha). Professor do Instituto Federal de Educação de Educação, Ciência e Tecnologia do Rio Grande do Norte. Contato: bruno.venancio@ifrn.edu.br.

** Doutorado em Letras (Estudos Linguísticos, Literários e Tradutológicos em Francês) pela Universidade de São Paulo (2008). Pós-Doutorado pela Universidade Paris 8 Vincennes-Saint Denis (2013). Professora Adjunto IV na Universidade Federal de Campina Grande. Contato: jsmariz22@hotmail.com.
} 
linguística em textos literários e em Brait (2000, 2010), discutiremos a importância do trabalho com textos literários no ensino da língua espanhola. Ao término, traçaremos algumas considerações que enfatizem a exequibilidade de uma abordagem de textos literários em aula de língua sem que se requeira a sua dicotomização.

Palavras-chave: Variação linguística. Literatura. Ensino de espanhol.

Abstract: We intend to revisit the place of the literary text in the teaching of foreign languages (or other). Such intent is anchored in the need of not establishing any dissociation between the two main basic axes of the Letters professional: Language and Literature. We bring reflections that we believe necessary for the formation of this professional, since working with both language and literature is a delicate and indispensable task, especially for the teacher of the area. Therefore, we will discuss the importance of the relationship between language and literature, from studies of linguistic variation in the teaching of Spanish in Brazil, placing emphasis on literature, the main reference point for such considerations. First, we discuss the linguistic variation in the teaching of Spanish, starting from a bibliographical research based on Moreno Fernández, (2010), Vilhena (2013), Andión Herrero (2008) and Lucchesi (2004) and a documental research based on the National Curriculum Guidelines for Secondary Education (2006). Anchored in the studies of Preti (2004) on linguistic variation in literary texts and Brait (2000; 2010), we will discuss the importance of working with literary texts in the teaching of Spanish. At the end, we will draw out some considerations which emphasize the feasibility of an approach to literary texts in language classes without dichotomizing them.

Keywords: Linguistic variation. Literature. Teaching Spanish.

\section{Considerações Iniciais}

No intento de refletir sobre o lugar do texto literário no âmbito do ensino de línguas estrangeiras (ou adicionais), este artigo traz à baila a relação 
intrínseca entre língua e literatura, partindo de uma necessidade de não dissociar esses dois grandes domínios. Tanto no âmbito dos estudos linguísticos, quanto dos estudos literários, profissionais ancorados nas correntes teóricas dessas duas grandes áreas têm se dedicado às reflexões que veem no conjunto, formado pela Língua (Linguística) e pela Literatura, o principal cerne motivador de reflexões. Entretanto, a necessidade de se pensar a língua e a literatura de maneira não dissociada não é, por assim dizer, uma visão nova, posto que essa problemática se constitui em uma inesgotável fonte de discussões, uma vez que está na origem da formação do profissional de Letras.

De fato, o centro do problema de qualquer pesquisa que busque trabalhar, de modo não dicotomizado, a língua e a literatura é o "como fazer?”. Isto porque, de um modo geral, o professor, seja da língua, seja da literatura, entende a importância da não dicotomização; todavia, encontra obstáculos, dentre os quais o mais evidente está estabelecido no próprio sistema acadêmico que precisa separar a língua da literatura para o ensino e formação de professores, por exemplo, nas faculdades de Letras, mesmo conscientes da essencial relação entre os dois. Essa é uma das principais sinalizações de pesquisadores nesse campo, a exemplo de Brait (2010, p. 725), ao nos lembrar que se trata de uma "parceria inquestionável, nata, atestada pela cumplicidade firmada entre criadores, criações e diferentes estudos da linguagem", [... mas, na qual ...] "muitas vezes opera-se uma dicotomia, por força de contingências institucionais, que dissimula a natureza dessa confluência incontornável", ratificando, assim, o quão delicada é esta perspectiva de trabalho.

Não obstante essa visão nos parecer ser ponto pacífico, de um modo geral, os profissionais da área entendem que a literatura e a língua, por serem indissociáveis, devem estar em um constante diálogo. Por essa razão que o "como" é, por certo, a principal inquietação, sobretudo, quando se considera as ponderações de Jakobson (2001), quando sugere que essa necessidade de separar as áreas pode ser ou por intolerância ou incompetência que cinge os professores tanto da literatura quanto da língua. Ora, não seria uma grande verdade avaliar que, para se trabalhar nessa perspectiva da indissociabilidade é, de fato, necessário ter certo "domínio" dos dois campos? Não seria por 
prudência e seriedade que, de um modo geral, os professores não se sentem "confortáveis" ao trabalhar sob esse prisma?

A partir desse ângulo, a questão volta a sobressair: como se pode trabalhar com a língua e com a literatura se, na grande maioria das vezes, o exercício da profissão é uma questão de escolha e / ou de afeição? Naturalmente, o curso da vida nos impõe escolhas. Entretanto, necessita-se, evidentemente, de um laço afetivo para que tais escolhas sejam definidas. Portanto, é óbvio que há de se ter uma estreita afinidade com o tema de conhecimento, segurança e até mesmo certa pré-disposição para uma maior dedicação ou para com a língua ou para com a literatura.

Nessa esteira, se retomarmos a assertiva de Brait (2010), anteriormente citada, por certo somos motivados a identificar, sob a ótica do ensino da línguas, um caminho todo especial para se propor vieses que permitam uma não separação entre os elementos dessa parceria inquestionável. É partindo dessas ponderações que entendemos ser necessário se fazer uma abordagem nas trilhas da não dissociação e, para isso, identificamos na didática das línguas estrangeiras um dos principais espaços que pode proporcionar o elo para essa não dicotomização. Buscando, então, uma perspectiva que não separe a literatura de sua língua, juntamos nossos interesses em variação linguística e na obra literária, buscando uma possibilidade de conduzir o aprendiz de língua espanhola, no contexto exolíngue brasileiro, a refletir sobre essa questão.

Tal reflexão se impõe ao considerarmos que a língua é um dos principais elementos culturais, assim como a literatura é, de modo preponderante, o registro linguístico-cultural de um povo. Nesse sentido, atualmente, pode-se dizer que é inevitável discutir questões concernentes à língua sem que se passe espontaneamente pela sua cultura; e, de modo muito especial, no ensino da língua/cultura estrangeira, dada a necessidade de ela ser conhecida na sua multiplicidade. Um dos vieses misteres para o aprendiz da língua espanhola é, certamente, o tema da variação linguística, pois, ligado a ela, estudiosos dessa matéria identificam um fértil solo que faz elo com a diversidade cultural e linguística. Esses estudos vêm ganhando um espaço significativo no ambiente acadêmico, de um modo mais claro, ao longo dos últimos anos, especialmente no âmbito de ensino de língua materna.

Assim, legitimar os estudos sobre as variedades linguísticas na sala de aula, além de, muitas vezes, ser uma necessidade do profissional, muito 
especialmente de linguistas, ajuda os aprendizes a entenderem o funcionamento de cada uma delas em seus diferentes contextos, sejam geográficas (diatópicas), sociais (diastráticas) ou estilísticas (diafásicas). A norma padrão se descaracteriza como o "ideal do falar" e se constitui como uma dessas expressões com seu propósito específico.

Em determinadas situações, profissionais interessados em manter a ideia de língua como um sistema homogêneo não veem positivamente essa nova abordagem de ensino, considerando as variações como desvios que devem ser eliminados de nossa fala. Isso pode ser observado em fóruns e eventos nos quais a questão é levantada. Geraldi (1996, p. 59) afirma que a escola "age como se a língua culta fosse estática, pronta, inabalavelmente infensa a seu uso nos processos interlocutivos". Essa abordagem pode ter trazido consequências para o preconceito e variantes e variedades linguísticas que não são contempladas no ensino, mesmo pertencendo à norma culta e, principalmente, àquelas que não estão incluídas nem na norma culta e nem na norma padrão. Em relação à estigmatização, Mollica e Braga (2004, p. 13) afirmam que toda língua apresenta

... variantes mais prestigiadas do que outras. Os estudos sociolingüísticos oferecem valiosa contribuição no sentido de destruir preconceitos lingüísticos e de relativizar a noção de erro, ao buscar descrever o padrão real que a escola, por exemplo, procura desqualificar e banir como expressão lingüística natural e legítima, em sua vã tentativa de homogeneizar a língua.

É certo que compreendemos que muitas dessas discussões se baseiam ou fazem referência ao ensino de língua materna, porém, perguntamo-nos: qual é o espaço que a variação linguística tem no ensino de línguas adicionais ${ }^{1}$ ? Somente o estudante de língua materna teria o direito de refletir sobre essas manifestações? A literatura, pouco trabalhada no enfoque comunicativo não

${ }^{1}$ Utilizamos ora língua (s) estrangeira(s) (LE), ora línguas adicionais (LA), sobretudo por termos como objeto de pesquisa, a língua espanhola que, no Brasil, é também língua de fronteira. 
se constituiria em um elemento motivador importante para essa reflexão? A partir dessas questões, este artigo se vê trazendo à discussão a relação não dicotomizada entre língua e literatura pelos caminhos da didática de línguas estrangeiras. Além disso, entendemos que é necessário refletir sobre a literatura e a variação linguística, que está ancorado, de maneira muito particular, no modelo de currículo multidimensional e interculturalista proposto por Serrani (2005).

Para avançar nas discussões, em um primeiro momento, arrazoamos sobre a importância da variação linguística no ensino de espanhol, no contexto brasileiro, apoiado pelas Orientações Curriculares Nacionais para o Ensino Médio (2006). Na sequência, nos apoiaremos nos estudos de Preti (2004) sobre a análise da variação linguística em textos literários, com a intenção de incluí-la em uma proposta de não dissociação da "parceria nata", desdobrando-se para o ensino de língua e literatura, no dizer de Brait (2000). Por fim, ao discorrermos em nossas considerações finais sobre o tema, retomamos o eixo central que motiva este artigo: a necessidade de se trabalhar no âmbito do ensino de línguas, a relação intrínseca entre a língua e a literatura no ensino de espanhol no Brasil.

\section{Variação Linguística e Ensino de Língua Espanhola no Brasil}

As Orientações Curriculares Nacionais de Língua Espanhola para o Ensino Médio - OCN (BRASIL, 2006) sugerem que professores da língua mudem a pergunta ¿qué español enseñar?, para ¿cómo enseñar el español, esta lengua tan plural?. A partir de uma visão de um espanhol heterogêneo, os autores das OCN (BRASIL, 2006) nos identificam problemas como a priorização do espanhol da Espanha, em detrimento do espanhol da América Latina, por exemplo, por ser considerado "melhor" ou "puro". Além disso, apontam para a falsa dicotomia que vê a língua espanhola como dois blocos opostos (Espanha / América). Conjuntura esta que é bastante criticada por Fontanella de Weinberg (1993), que define o espanhol americano como um conjunto de variedades linguísticas faladas na América, definidas geográfica e historicamente, não esquecendo o complexo e variado caráter do processo de colonização nem suas implicações linguísticas. 
Além disso, a preferência pela variedade castellana, representada pela fala de Madri, é gerada por outros fatores. Moreno Fernández (2010), por exemplo, afirma:

Muchos profesores universitarios brasileños han recibido formación o han perfeccionado sus conocimientos profesionales en España, por lo que no es extraña una actitud favorable hacia la variedad castellana y hacia su uso en las aulas, actitud y uso reforzados por la amplia oferta de materiales didácticos elaborados y publicados desde España. ${ }^{2}$ (MORENO FERNÁNDEZ, 2010, p. 185).

Por certo, o profissional de LE estará em busca de aperfeiçoamento linguístico no país "sede" da língua. Isso acontece com a língua francesa, quando os estágios de formação são, em sua grande maioria, ofertados pelo governo francês; ou com a língua inglesa, que chama os profissionais da língua ou para os Estados Unidos ou para a Inglaterra. Cabe, entretanto, ao profissional "formado" no país de origem da língua e possuidor de uma visão mais ampla dela, identificar a sua realidade e propor um ensino que, de fato, atenda ao seu público-alvo. Por conseguinte, mesmo havendo essa espécie de favorecimento, conforme nos sinaliza Moreno Fernández (2010), é também ele quem reforça que o ensino de espanhol deve estar centrado nas necessidades imediatas dos alunos, trazendo à discussão um fator importante na elaboração do programa de espanhol: o entorno brasileiro.

Con todo, más allá de la procedencia geolingüistica, más allá de las actitudes proclives hacia esta o aquella variedad, la realidad sociolingüistica de Brasil ofrece un horizonte general en el que el español de América ha de alcanzarse con un especial protagonismo. Un español de América que podrá hablarse con más o menos acento, con más ornenos calcos sintácticos es lo de menos, pero que debe hacer fácil y fluida la

\footnotetext{
Muitos professores universitários brasileiros receberam formação ou aperfeiçoaram seus conhecimentos profissionais na Espanha, o que justifica uma atitude favorável em relação à variedade castelhana e a seu uso na sala de aula, atitude e uso reforçados pela ampla oferta de materiais didáticos elaborados e publicados pela Espanha Todas as traduções são de nossa autoria, salvo menção contrária.
} 
comunicación con los hispanohablantes de los países socios del MERCOSUR. [...] son siempre las necesidades y expectativas de los aprendices para qué quieren aprender español, dónde lo van a usar, con quién se van a comunicar, con qué fines las que han de juzgar un programa de español como adecuado o como improcedente. ${ }^{3}$ (MORENO FERNÁNDEZ, 2010, p. 185-186).

Tal assertiva legitima a necessidade de o professor conhecer a sua realidade para, a partir dela, possibilitar um curso que realmente atenda às demandas do seu ambiente de ensino. É a partir dessa espécie de perfil do público-alvo que pode ser possível propor um ensino sem dicotomização entre o espanhol europeu e o latino. Outra possiblidade para solucionar o problema dessa dicotomia, apontado pelas OCN (BRASIL, 2006), pode ser a opção pelo "espanhol neutro" ou Español estándar, eliminando marcas distintivas de diversas regiões. Enquanto questão presente nesse documento, é indispensável também que se considere a difícil padronização da língua, exemplificada no caso do tratamento de segunda pessoa do plural informal. Acreditamos que, para o tratamento de segunda pessoa do singular informal, esse tema é ainda mais intricado, devido às possibilidades de realização.

Nessa perspectiva, Carricaburro (1997) nos explica os usos de "tú", "vos" e "usted", optando por uma divisão por países. Entretanto, essa autora, inclusive, ratifica que os usos dentro de um mesmo país podem se dar de maneiras diferentes por variáveis e situações de interlocução diversas. Geralmente, os livros didáticos de língua espanhola publicados no Brasil não costumam contemplar o pronome de tratamento "vos" ou costumam relegá-lo apenas a uma "curiosidade", embora esteja mais estendido que o pronome de tratamento vosotros, exclusivo da variedade peninsular

${ }^{3}$ Contudo, além da procedência geolinguística, além de determinadas atitudes a uma ou outra variedade, a realidade sociolinguística do Brasil oferece no horizonte geral do espanhol americano, um papel de protagonista. Um espanhol da América que poderá ter mais ou menos sotaque, com mais ou menos calcos sintáticos, mas que deve facilitar a comunicação com os hispanófonos dos países sócios do MERCOSUL. [...] São sempre as necessidades e expectativas dos aprendizes para que querem aprender espanhol, onde vão usá-lo, com quem vão se comunicar, com que fins um programa de espanhol deve ser considerado adequado ou improcedente. 
(VENÂNCIO DA SILVA; ALVES DA SILVA, 2007), por uma questão histórica e de preconceito linguístico, e também porque muitos deles, como já dito, foram produzidos na Espanha, o grande mercado editorial de livros de espanhol.

Então, em se tratando dessa delicada relação entre língua e literatura, no contexto exolíngue de ensino do espanhol, não se pode deixar de trazer à discussão a importância do livro didático enquanto instrumento norteador no ensino, constituindo-se em um dos principais suportes para professores de línguas estrangeiras. Por esse prisma, Vilhena (2013, p. 64-74) coloca em questão a simplificação da língua espanhola no material didático quando se adota esse espanhol abstrato, a ponto de construir uma alteridade, adulterando e/ou desprezando a convivência e o confronto de vozes no universo hispanófono. Esse pesquisador ainda aponta que os materiais didáticos, mesmo dentro dessa visão de abstração e homogeneização da língua, ainda se encontram presos ao espanhol europeu como modelo de variedade e léxico.

Entretanto, Eres Fernández (2002, p. 10), por exemplo, não acredita que a predominância de uma variante no material didático se constitua em um problema, visto que o professor tem liberdade de apresentar outras variantes aos seus estudantes, entendendo o livro como um recurso a mais na sala de aula. A autora entende que o professor terá mais trabalho porque terá que selecionar materiais que reflitam diferentes modalidades de língua e de cultura das que são encontradas no livro, podendo ser textos de leitura, vídeos, gravações de áudio e, até mesmo, a própria variedade do professor.

Sobre esse papel, estudo de Andión Herrero (2008)sobre o modelo que os professores de espanhol adotam no ensino da língua sinaliza a necessidade de que a formação do corpo docente seja adequada para que se possa refletir sobre diversas questões relativas ao ensino, entre elas a variação e seu lugar na sala de aula.

En los profesores - o aspirantes a serlo - ha calado la razonable idea de que no basta con ser nativo o tener un dominio cuasi nativo del español; hay que estar bien preparado y saber más de planificación curricular, adquisición, metodología, gramática, fonética y léxico aplicados a la enseñanza, pragmática, 
lenguajes específicos... y variedades de la lengua. ${ }^{4}$ (ANDIÓN HERRERO, 2008, p. 168).

Desse modo, pode-se ratificar que a problemática das variedades da língua se configura em uma questão vital para o professor, assim como o léxico ou a fonética. Entretanto, é a própria Andión Herrero (2008, p. 169) quem afirma que os professores não negam a heterogeneidade do espanhol, porém possuem um conhecimento desigual relacionado à variação linguística, o que os leva, muitas vezes, a não conseguirem explicar casos de variação dialetal, gerando incerteza e estresse, além de conduzi-los a respostas equivocadas. Alguns professores podem, inclusive, corrigir seus aprendizes que utilizam variantes que eles desconhecem e que foram adquiridas por professores anteriores, falantes de variedades diferentes, gerando, assim, uma atitude negativa do aluno.

Se analisarmos bem os pontos que são colocados por diversos autores, e até mesmo por documentos oficiais como as OCN (BRASIL, 2006), a variação linguística no ensino de espanhol não chega a ser um problema, e várias são as formas de levá-la ao estudante, mesmo quando o livro didático impossibilita tão importante tarefa. Porém, partilhamos do mesmo ponto de vista de Andión Herrero (2008), ao asseverar que a formação adequada do professorado é um ponto decisivo, seja na área de sociolinguística ou dialetologia, como qualquer outra. Parece-nos que as outras disciplinas mencionadas pela autora constam na maior parte dos currículos dos cursos de Letras, posto serem poucos os cursos que possuem uma disciplina que trabalhe questões relativas à variação linguística em língua estrangeira, além de haver, em nosso país, um número pouco expressivo de artigos acadêmicos produzidos nessa área, que proponham reflexões sobre tal problema carente de mais pesquisas. Isso é registrado em estudo de Daher e Sant'Anna (1998, p. 112), ao assegurarem que $75 \%$ dos professores de três universidades

${ }^{4}$ Entre os professores de espanhol - ou aspirantes - adentrou a ideia razoável que não basta ser nativo ou ter um domínio quase perfeito do espanhol, tem que estar preparado e ter conhecimento de planificação curricular, aquisição, metodologia, fonética e léxico aplicado ao ensino, pragmática, gramática, linguagem específicas... e variedades da língua. 
públicas do Rio de Janeiro relataram que ensinam o espanhol mais próximo da Espanha, excluindo os aprendizes de nível superior e em formação para ministrar aulas de língua espanhola da possibilidade do contato com outras normas.

É inequívoco que ensinar uma língua adicional, atualmente, exige mais que o domínio da gramática ou que sejam reproduzidas situações comunicativas que os alunos memorizem e reproduzam como uma simples criação de hábitos. Courtillon (1984) afirma:

Apprendre une langue étrangère c'est apprendre une culture nouvelle, des modes de vivre, des attitudes, des façons de penser, une logique autre, nouvelle, différente, c'est entrer dans un monde mystériuex au début, comprendre les comportements individuels, augmenter son capital de connaissances et d'informations nowvelles, son propre niveau de compréhension. ${ }^{5}$ (COURTILLON, 1984, apud MANNA, 2009, p. 211).

As competências que nossos estudantes devem atingir são múltiplas quando pensamos na proposta intercultural para o ensino de línguas adicionais, exigindo-se que o professor transite por diversas áreas. Lucchesi (2004, p. 171-179) aponta que a competência linguística do falante é multidialetal, ou seja, que ele é capaz de lidar com a heterogeneidade do sistema, sem problemas de decodificação. Evidentemente, o autor faz referência ao falante nativo de uma dada língua materna que, ao longo de sua vida, entrou em contato com sistemas linguísticos de diversas comunidades de fala diferentes da sua, enriquecendo seu repertório linguístico para que a eficácia na comunicação não seja comprometida. Ao beber dessa fonte, propomos uma transposição desse conceito para o ensino de línguas adicionais, no qual o professor deve facilitar o contato com diversas variedades da língua meta para que o aluno tenha a capacidade de decodificar essa heterogeneidade e

${ }^{5}$ Aprender uma língua estrangeira é aprender uma nova cultura, modos de viver, atitudes, maneiras de pensar, uma outra lógica, nova, diferente, é entrar em um mundo misterioso no começo, compreender comportamentos individuais, argumentar seu capital de conhecimento e informações novas, seu próprio nível de compreensão (COURTILLON, 1984 apud MANNA, 2009, p. 211). 
não comprometer a comunicação, entendendo a variação, tanto em sua língua materna como na língua que está aprendendo, como um fenômeno comum e sistemático.

Ao incluir o conceito de competência multidialetal, não sugerimos que o ideal de língua que deve ser alcançado seja a de um falante nativo, porém não podemos deixar de refletir sobre as necessidades de comunicação dos alunos na língua meta e nas interferências que podem ocorrer caso essa língua seja ensinada como um sistema homogêneo, desvinculado das culturas e valores de uma sociedade. Nesse caso, voltamos à ponderação de Eres Fernández (2002, p. 10), quando lembra que o professor pode (e deve, em nossa opinião) proporcionar o contato com diversas variedades através de alguns recursos que, em nosso trabalho, se deterá na rica literatura em língua espanhola, que exploraremos no próximo tópico.

\section{A Relação entre Literatura e Variação Linguística na Aula de Línguas Adicionais}

Ao ponderarem sobre a dicotomização do ensino de língua e literatura, tanto Brait (2000) quanto Serrani (2005) coincidem, não aleatoriamente, no uso de uma palavra frequente para os variacionistas: "mudança", pois toda mudança é resultado de uma variação. A literatura deve ser encarada como uma das possibilidades de exploração e utilização da língua para diversos fins, caracterizando e pontuando mudanças em diferentes momentos históricos, em diferentes povos, em diferentes línguas (e por que não, em diferentes variedades linguísticas de uma mesma língua?), para justificar a existência e a natureza humana dentro da sua unidade e de sua diversidade.

Para retomar a discussão sobre a formação adequada de professores de línguas adicionais, baseado na "parceria língua-literatura", Brait (2000, p. 197) afirma:

... o profissional de Letras terá que conhecer muito bem a língua, as suas variantes, a sua norma culta. Mas terá também de conhecer literatura, como uma das formas de expressar essa língua e tudo que possa significar. Terá ainda de estar atento às teorias da linguagem em geral para ser capaz de enfrentar textos e fazer deles seu instrumento de ver e mostrar o mundo. (BRAIT, 2000, p. 197) 
Do ponto de vista pedagógico, o trabalho com a literatura enriquece o ensino de língua e a recíproca é verdadeira. A fragilidade da separação é evidente, principalmente a partir dos anos 1970, quando a estudiosa explica que passou a existir uma nova compreensão de linguagem nos estudos de Letras, reconhecendo e valorizando a variação linguística, sendo abordada "a partir das categorias de texto, incluindo o verbal e o não-verbal, o literário e o não-literário, a norma cultura e as demais normas" (BRAIT, 2000, p. 196).

Nesse sentido, de acordo com Preti (2004, p. 117-118), inúmeras pesquisas linguísticas foram realizadas através da literatura, que, na ausência de tecnologias para a documentação da língua na modalidade oral, como gravadores, serviu como corpus, visto que os narradores e personagens, de alguma forma, reproduziam a realidade linguística em diversas situações de interação de diversos momentos históricos. Muitos autores foram influenciados pela oralidade e alguns chegaram a estudar fenômenos de variação nas comunidades de fala, registrando, assim, através da linguagem em suas obras, a variação social e psicológica, especialmente depois do século XIX, com a valorização das classes mais populares. Românticos, realistas e naturalistas caracterizavam suas obras com maior realidade nos diálogos de ficção com marcas da oralidade. Por certo, não estamos diante de uma "língua literária" como uma "língua exemplar", ou a da norma padrão, mas da possibilidade que alguns estilos literários nos trazem para explorar, por exemplo, a espontaneidade da fala cotidiana, estratégia intencional do escritor que depende, sobretudo, de seus objetivos de natureza estética (PRETI, 2004, p. 120-121).

Para a análise da variação linguística em obras literárias, Preti (2004, p. 138-149) propõe dois modelos que podem ser seguidos: a macroanálise e a microanálise. A primeira se detém a analisar as variáveis sociais dos falantes, tais como faixa etária, sexo (gênero), profissão/ocupação, escolaridade, origem geográfica etc. Essas variáveis são conhecidas da Sociolinguística Variacionista, que trabalha com essas "etiquetas" para caracterizar as comunidades de fala. Junto a essas variáveis, esse estudioso propõe que se associe, também, as condições de comunicação, que englobaria o local onde a comunicação foi realizada, o grau de intimidade entre os falantes, o tema, para que, assim, possamos classificar a linguagem como culta, comum, popular, vulgar, dentre outras. 
A segunda, mais relacionada à Sociolinguística Interacional, detém-se ao ato de fala em si, levando em consideração aspectos cognitivos e estruturas de expectativas, ou seja, o que esperamos que o falante fale e através de que tipo de linguagem. Para dar conta dessa análise, a interação verbal deve ser enquadrada, podendo ser uma ofensa, uma malícia, uma situação de carinho ou desprezo, que será percebida a partir do ritmo, da intensidade da voz, do tom irônico e dos vocábulos adequados ou não dos falantes. Em outras palavras, situar o aprendiz a respeito de como se dá a comunicação na obra literária, a partir de fatores internos e externos à linguagem e à produção do escritor enquanto objetivo estético, ultrapassando o tratamento estrutural da linguagem, como circular os verbos no pretérito indefinido do indicativo ou preencha os espaços do conto de Gabriel García Márquez com o presente do subjuntivo.

Em uma discussão sobre língua comum e língua literária, Guillamas (2002, p. 193-196) discute, de maneira mais atenta, a noção de intencionalidade, enquanto principal diferenciador entre ambas; ou seja, a primeira (a língua) tem como finalidade a comunicação, enquanto a segunda (a literatura) é um produto artístico, cujo valor vai muito além do que as palavras significam como mensagem. A estudiosa ainda afirma que língua e literatura estiveram, durante um tempo, inter-relacionadas, inclusive porque a literatura faz uso do código da língua comum, porém aponta relações hierárquicas entre ambas, sendo a primeira, o código ou norma a se seguir e, a segunda, um desvio.

Caminhando para as suas conclusões, nesse texto, a pesquisadora retoma o tema central de nossas ponderações e já citado no tópico anterior: a formação do professor. No que se refere ao estabelecimento de limites entre a língua literária e a comum, Guillamas (2002, p. 195) afirma que " $E s$ tarea del docente establecer una linea a seguir, y tomar dicha decisión implica necesariamente

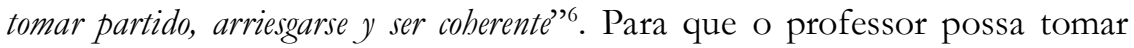
certas decisões, sua prática deve estar atrelada à pesquisa, promovendo sempre reflexões que vão ajudá-lo a tomar partido, a arriscar-se, sem, no entanto, deixar de ser coerente. A leitura de bibliografia especializada e a troca de

${ }^{6}$ É tarefa do docente estabelecer uma linha a se seguir, e tomar essa decisão implica em tomar necessariamente um partido, arriscar-se e ser coerente (GUILLAMAS, 2002, p. 195). 
experiência entre docentes são peças fundamentais para que o professor possa "provar novas experiências" na sua sala de aula.

Um capítulo de Lobato (2009, p. 85-102) dedicado a discorrer sobre os aspectos de cortesia verbal na prosa do escritor espanhol Alonso Zamora Vicente (Madri, 1 de fevereiro de 1916 - 14 de março de 2006) é de grande relevância para que retifiquemos que as marcas de oralidade aparecem na literatura. Especificamente sobre esse escritor espanhol, Lobato (2009, p. 85-86) afirma que sua prosa corresponde à oralidade mais genuína das ruas (de Madri), de diversas estratificações linguísticas, espontâneas e vivas pelos seus falantes, afastando-se do que o senso comum entende por "língua literária".

Nesse estudo, o autor explica que tipo de língua é usado na prosa de Alonso Zamora Vicente, a partir de características como a coloquialidade, as relações e estratégias de cortesia, as fórmulas de tratamento e os tipos de saudações, despedidas, apresentações, felicitações, pedidos, entre outras funções comunicativas, sempre analisando a partir de exemplos retirados de suas obras. Estudos como estes são importantes sustentáculos para os professores que desejam inter-relacionar o ensino de língua ao de literatura, incluindo, desse modo, a variação linguística, visto que as marcas de oralidade estarão relacionadas a um momento histórico, a um espaço geográfico e à ideologia de uma comunidade que faz uso desse sistema linguístico nessa obra literária, considerando sempre aspectos estéticos, além da função expressiva, pouco valorizada no ensino de línguas adicionais.

Evidentemente, o estudo de Lobato (2009) não é único no universo da hispanofonia a abordar a questão, mas se estabelece como uma das mais importantes pesquisas que abordam a inerente relação da língua com a literatura e, particularmente: variação linguística e literatura.

\section{Considerações Finais}

Ao longo desse artigo, trouxemos ponderações a respeito da necessidade da não separação entre os dois principais eixos de trabalho do profissional de Letras, lembrando que há um caminho especial que pode favorecer essa abordagem entre a língua e a literatura: a didática de línguas, uma vez que, para se ensinar a língua, é necessário ter conhecimentos que vão 
além daquele que tem o usuário da língua. Colocamo-nos nesse vestígio e encontramos na variação linguística, no âmbito do ensino de espanhol, um espaço que permite conduzir o aprendiz dessa língua a perceber a importância de se trabalhar, de modo homogêneo, a literatura.

Ressaltamos o quanto a língua e a literatura não deveriam permanecer dicotomizados no ensino, sendo de vital importância inter-relacioná-las a partir de uma abordagem intercultural, na qual a gramática ou os diálogos de situações como "compras no supermercado" ou "pedindo informações" não sejam seu único fim. A partir dessa abordagem, pensamos na variação linguística, esquecida nas aulas de línguas adicionais, como mais um componente interdependente nesse processo transdisciplinar.

Integrar a variação por meio da literatura com base na proposta de Preti (2004), expondo características macro e microlinguísticas, enriquece, a partir do nosso ponto de vista, que tem como objetivo uma visão processual da linguagem, na qual não podemos pensar e nem ensinar ou reproduzir a ideia de que a língua é um sistema homogêneo para os alunos, desvinculada de uma ou mais sociedades. Portanto, acreditamos na importância e no determinante papel que têm as reflexões sobre a formação de professores nos cursos de Letras, sobretudo quando se trata da formação de professores de línguas estrangeiras modernas, posto que a língua está diretamente associada à cultura e que, também por essa razão, deveria ter um caráter mutidisciplinar, respondendo às necessidades imediatas do corpo discente.

Com isso, ressaltamos o papel do livro didático, enquanto elemento/ suporte norteador na sala de aula, a responsabilidade de que precisa e, logo, deve oportunizar, e a diversidade linguística e cultural das línguas metas de seus aprendizes. Apesar de estarmos de acordo com Eres Fernández (2002, p. 10) no que se refere ao papel do professor e à exposição às variedades linguísticas, para que as mudanças sejam efetivadas no ensino e para que a diversidade linguística e cultural ocupe o lugar de componente interdependente dos demais, os livros didáticos publicados no Brasil devem também atender às necessidades dos alunos. Tudo isso deve ser pensado, de maneira muito mais particular, em nosso contexto de país de língua portuguesa rodeado de países hispanófonos.

Reafirme-se, pois, que trabalhar o texto literário em aula de língua é, de fato, tema de debates também porque questões metodológicas e 
tradicionais provocaram uma separação (no transcurso dessa história) entre literatura e língua. Evidentemente que, de maneira particular, os cursos de formação em Letras precisaram provocar essa cisão como se essas duas áreas das ciências humanas fossem completamente distintas. Acredita-se, pois, que foi essa divisão que deixou como herança certa resistência ao trabalho unificado da literatura em aula de língua.

\section{Referências}

ANDIÓN HERRERO, M. A. La variedad del profesor frente al modelo de enseñanza: convergencias, divergencias y actitudes. Actas del XIX Congreso de ASELE. Madrid, 2008. p. 167-183.

BRAIT, B. Língua e literatura: uma falsa dicotomia. Revista da Anpoll, v. 8, p. 187-206, 2000.

BRAIT, B. Língua e literatura: saber com sabor. Estudos Linguísticos, São Paulo, v. 39, n. 3, p. 724-735, maio/ago. 2010.

BRASIL. Ministério da Educação. Orientações Curriculares Nacionais para o Ensino Médio (OCEM). Conhecimentos de Espanhol. Brasília: Secretaria de Educação Básica, 2006. Disponível em: < http://bit.do/bFJFi>. Acesso em: 3 out. 2013.

CARRICABURRO, N. Las fórmulas de tratamiento en el español actual. Madrid: Arco Libros, 1997.

DAHER, M. C. F. G.; SANT’ANNA, V. L. A. “¿Lo ajeno, más que lo próprio parece bueno?" Um estudo das atitudes dos professores de espanhol como LE no Rio de Janeiro. Linguagem \& Ensino, Pelotas, v. 1, n. 1, p. 105-114, 1998.

ERES FERNÁNDEZ, G. M. Las variantes del español en la nueva década: ¿todavia un problema para el profesor? Actas del VIII Seminario de Dificultades de la enseñanza del Español a Lusohablantes: Registros de lengua y lenguajes específicos. Brasília: Embajada de España en Brasil; Consejería de 
Educación y Ciencia; Ministerio de Educación, Cultura y Deporte de España, 2002.

FONTANELLA DE WEINBERG, M. B. El español de América. 2. ed. Madrid: Mapfre, 1993.

GERALDI, J. W. Concepções de linguagem e ensino de português. In: GERALDI, J. W. (Org.). O texto na sala de aula. São Paulo: Ática, 1984. p. 39-46.

GUILLAMAS, R. R. Lengua literaria - lengua común. Actas del VIII Seminario de Dificultades de la enseñanza del Español a Lusohablantes: Registros de lengua y lenguajes específicos. Brasília: Embajada de España en Brasil; Consejería de Educación y Ciencia; Ministerio de Educación, Cultura y Deporte de España, 2002.

LOBATO, J. S. Aspectos de la cortesía verbal en la prosa de Alonso Zamora Vicente. In: LOBATO, J. S.; DIEGO, V. A. de; GÓMEZ, R. P. Aspectos del español actual: descripción, enseñanza y aprendizaje (L1 y L2). Madrid: SGEL, 2009.

LUCCHESI, D. Sistema, mudança e linguagem: um percurso na história da lingüística moderna. São Paulo: Parábola, 2004.

JAKOBSON, R. Lingüistica e comunicação. Tradução Isidoro Blikstein; José Paulo Paes. São Paulo: Cultrix, 2001.

MANAA. G. L'enseiguement/apprentissage du français langue étrangère et la quête d'une nouvelle approche avec les autres cultures. Synergies, Algérie, n. 4, p. 209-216, 2009.

MOLLICA, M. C.; BRAGA, M. L. Introdução à Sociolingüistica: o tratamento da variação. São Paulo: Contexto, 2004.

MORENO FERNÁNDEZ, F. Las variedades de la lengua española y su enseñanza. Madrid: Arco Libros, 2010.

PRETI, D. Estudos de lingua oral e escrita. Rio de Janeiro: Lucerna, 2004. 
SERRANI, S. Discurso e cultura na aula de língual curriculo - leitura - escrita. Campinas: Pontes, 2005.

VENÂNCIO DA SILVA, B. R. C.; ALVES DA SILVA, R. El voseo en los libros didácticos de E/LE en Brasil. Boletin de la Asociación Argentina de Docentes de Español, n. 25, nov./dic. 2007.

VILHENA, K. B. F. Sobre a invisibilidade das variedades linguísticas latino-americanas no livro didático nacional para o ensino de língua espanhola. In: ZOLIN-VESZ, F. (Org.). A (in)visibilidade da América Latina no Ensino de Espanhol. Campinas: Pontes, 2013. p. 63-76.

Recebido em: 09/06/2015

Aceito: $18 / 11 / 2015$ 